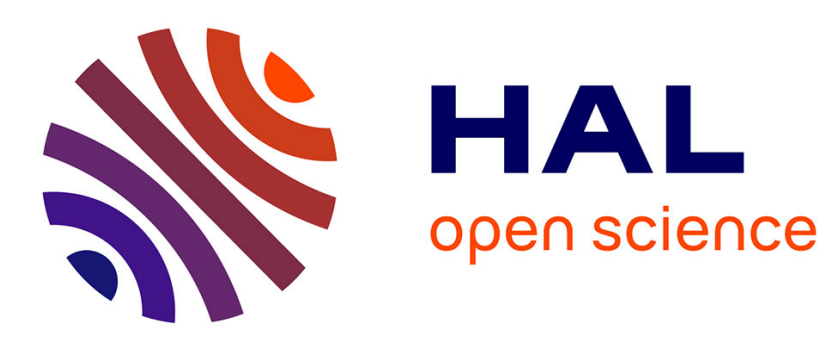

\title{
Microwave Monitoring of Single Cell Monocytes Subjected to Electroporation
}

\author{
Amar Tamra, David Dubuc, Marie-Pierre Rols, Katia Grenier
}

\section{To cite this version:}

Amar Tamra, David Dubuc, Marie-Pierre Rols, Katia Grenier. Microwave Monitoring of Single Cell Monocytes Subjected to Electroporation. IEEE Transactions on Microwave Theory and Techniques, 2017, pp.1 - 7. 10.1109/TMTT.2017.2653776 . hal-01463946

\section{HAL Id: hal-01463946 \\ https://hal.laas.fr/hal-01463946}

Submitted on 9 Feb 2017

HAL is a multi-disciplinary open access archive for the deposit and dissemination of scientific research documents, whether they are published or not. The documents may come from teaching and research institutions in France or abroad, or from public or private research centers.
L'archive ouverte pluridisciplinaire HAL, est destinée au dépôt et à la diffusion de documents scientifiques de niveau recherche, publiés ou non, émanant des établissements d'enseignement et de recherche français ou étrangers, des laboratoires publics ou privés. 


\title{
Microwave Monitoring of Single Cell Monocytes Subjected to Electroporation
}

\author{
Amar Tamra, Associate Member, IEEE, David Dubuc, Member, IEEE, Marie-Pierre Rols, \\ and Katia Grenier, Member, IEEE
}

\begin{abstract}
This paper presents the monitoring of single cells subjected to electroporation using microwave dielectric spectroscopy. The experimental results showed first a clear distinction between two cell states: viable cells and affected ones by a chemical treatment (Saponin). It also pointed out a high correlation $\left(R^{2}>0.94\right)$ with biological standard techniques in detecting the two types of electroporation: the reversible and irreversible ones. The developed microfluidic and microwavebased sensor exposes a decrease in the capacitive and conductive contrasts of the investigated single cells treated by irreversible electroporation indicating damages at the cellular level, while cells under reversible electroporation present a similar dielectric response to that of the nontreated cells. This result corresponds to results frequently employed in biological studies. More interestingly, a study of the kinetics of the cell's damage induction over time, by electroporation, has been experimentally done, which makes microwave dielectric spectroscopy an attractive technique for cell's electroporation researches.
\end{abstract}

Index Terms-Biosensor, dielectric spectroscopy, electroporation, microwave analysis, single cell.

\section{INTRODUCTION}

$\mathbf{C}$ ELL membranes are phospholipidic bilayers, that constitute barriers between the intracellular and the extracellular domains. Accessing the intracellular compartments of cells, using electroporation for instance, has shown a strong interest for various biomedical applications. Electroporation notably enables the internalization of foreign molecules into the cell, elimination of microorganisms, insertion of proteins into cell membrane, and cells fusion [1]. The development of a physical method, ElectroPoration EP (or ElectroPermeabilization), that consists in using the application of external well controlled electric field pulses [2], enabled to transiently or permanently permeabilize the plasma membrane. This process allows the entry or exit of specific molecules of interest, such as small molecules (drugs in Electrochemotherapy) and

Manuscript received July 5, 2016; revised September 28, 2016, November 21, 2016, December 14, 2016, and January 5, 2017; accepted January 6,2017 . This work was supported in part by the French Midi-Pyrénées region with the Université Fédérale Toulouse Midi-Pyrénées and in part by LAAS-CNRS micro and nano technologies platform, member of the French RENATECH network.

A. Tamra is with the Laboratory of Analysis and Architecture of Systems, National Scientific Research Center, 31400 Toulouse, France, and also with the Institute of Pharmacology and Structural Biology, 31077 Toulouse, France (e-mail: atamra@laas.fr).

D. Dubuc and K. Grenier are with the Laboratory of Analysis and Architecture of Systems, National Scientific Research Center, 31400 Toulouse, France (e-mail: dubuc@laas.fr; grenier@laas.fr).

M.-P. Rols is with the Institute of Pharmacology and Structural Biology, 31077 Toulouse, France (e-mail: rols@ipbs.fr).

Color versions of one or more of the figures in this paper are available online at http://ieeexplore.ieee.org.

Digital Object Identifier 10.1109/TMTT.2017.2653776 macromolecules (genetic material in Electrogenotherapy) into the cell cytoplasm [3]. Electroporation depends on a number of electric pulse parameters, such as intensity, number, duration, and repetition frequency of the pulses [4]-[6]. Electric field intensity is the deciding parameter inducing permeabilization. Rols and Teissié [7] reported that an increase in the number of pulses enhances the rate of permeabilization and increasing the duration of the pulses is crucial for the penetration of macromolecules compared with small molecules. Pucihar et al. [8] showed that the uptake of exogenous molecules into cells in vitro stays at similar levels even at frequencies up to $8.3 \mathrm{kHz}$ compared with the classical used frequency of $1 \mathrm{~Hz}$. After all, the choice of the electrical parameters to be used depends on the type of application, the treated cells or organs and the type of molecules used.

The first studies on electroporation reported cell death caused by the irreversible permeabilization (IrReversible Electroporation-IRE) of cell membranes. This approach is nowadays used in tumor ablation. It consists in applying to the cell short pulses at high voltage, causing the formation of permanent nanometric defects in the cell membrane. This permanent permeability leads to changes in cellular homeostasis and cell death [9]. Unlike the IRE, reversible permeabilization of the plasma membrane can be induced by applying external electrical impulses with well-chosen amplitude and duration (few $\mathrm{kV} / \mathrm{cm}$ and few microseconds), to facilitate the passage of little or nonpermeant molecules, without affecting cell viability [7]. Once the electric pulses are submitted to the cell, its membrane's electric potential $\Psi$ is modified. The permeabilization occurs when the sum of the native transmembrane potential $\Delta \Psi o$ and the induced transmembrane potential $\Delta \Psi i$ exceeds a threshold value $(-200 \mathrm{mV})[10]$.

Despite progress in the field of electroporation and electrochemotherapy, enlarging our knowledge about the associated mechanisms and kinetics remains of high interest. The routine methods used for the evaluation of the effect of electroporation on the cells permeability and viability are indeed effective. However, they require the large amount of time as well as the large volumes of biomaterials, but above all are abusive for the cells. For example, when using classical microscopy combined to the use of fluorescent markers (calcein AM (AM = acetoxymethyl), Propidium Iodide (PI), and so on.), the cells can no longer be used for additional tests. The same problem applies when using biochemical tests, such as Tetrazolium Reduction Assay MTT (3-(4, 5-dimethylthiazolyl-2)-2, 5-diphenyltetrazolium bromide), that reflects the cell's mitochondrial activity. 
In addition to these techniques, the biological research domain is witnessing the development and the employment of new physical methods, such as atomic force microscopy, electronic microscopy, and electrical spectroscopy. The study of the electrical properties of biological materials has shown indeed a wide interest [11], [12]. At low frequencies, up to few hundreds of $\mathrm{MHz}$, the membrane's state can be revealed [13], [14]. Nevertheless, the efficacy of the technique of electrical impedance spectroscopy is limited at the cell membrane level. Whereas by applying high frequency electromagnetic waves (beyond hundreds of $\mathrm{MHz}$ ), the waves can overcome the cell membrane and interact directly with the intracellular compartments [15], [16]. In addition, the demonstration of microwave sensing at the single cell level has already been performed [17]-[21]. It enables the evaluation of cells suspension heterogeneity, which is of high interest in bio-physical processes investigation and understanding.

This paper reports our work on a microwave and microfluidic-based biosensor, able to perform dielectric spectroscopy of the single cell and to monitor the intracellular effects of both reversible and irreversible electroporations. Compared with [22], reversible electroporation sensing with microwave dielectric spectroscopy is demonstrated. Supplementary information on protocol, dielectric threshold determination and electroporation results are also given.

This paper is organized as follows. Section II shows the microdevice architecture combining microwave and microfluidic functionalities, as well as the experimental protocol used. Section III describes the choice of the electrical parameters used for electroporation. Microwave modeling of a single cell, the calibration procedure and the electrical response of a single cell to a chemical treatment (saponin) are presented in Section IV. Sections V and VI will show, respectively, the efficacy of the dielectric spectroscopy technique in reflecting cell state after reversible EP and IRE, and the experimental microwave monitoring of the kinetics of the cells response to irreversible electroporation. The solid correlation between the microwave readout and the results obtained with biological methods sharply reflects the efficacy of the microwave dielectric spectroscopy technique to reveal the kinetic effects of cell's electroporation. Finally Section VII summarizes and concludes this paper.

\section{Microwave Biosensor AND EXPERIMENTAL PROTOCOL}

\section{A. Microwave Microfluidic Biochip}

This paper is based on a microwave and liquid-based sensor developed by Chen et al. [17], that presents a microfluidic channel allowing the process of biological materials (pure culture medium or medium with cytotoxic agents or suspension of cells). This microwave sensor is moreover markerless, contact-less, and permits to analyze the single cell within its culture medium. The microdevice, shown in Fig. 1, consists of a coplanar waveguide with a capacitive gap in the center. A microfluidic channel is placed on top of the microwave circuit and a mechanical trap is located over the capacitive gap, which captures one single cell. When the electromagnetic waves interact with the biological sample, a reflection of the

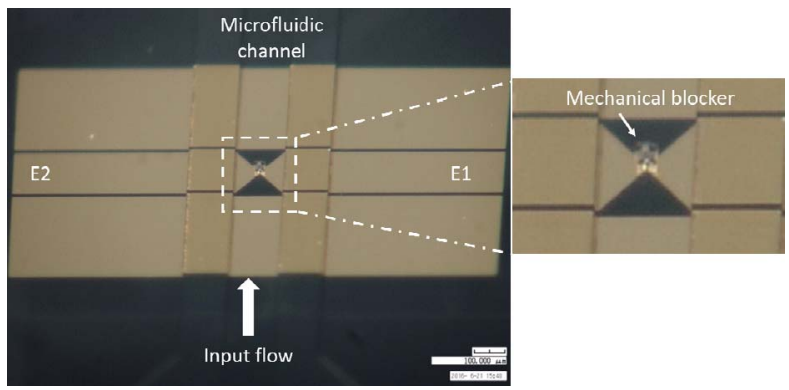

Fig. 1. Microwave miniature biosensor with a coplanar waveguide and a microfluidic channel placed on top; the biological cell is blocked with a mechanical trap.

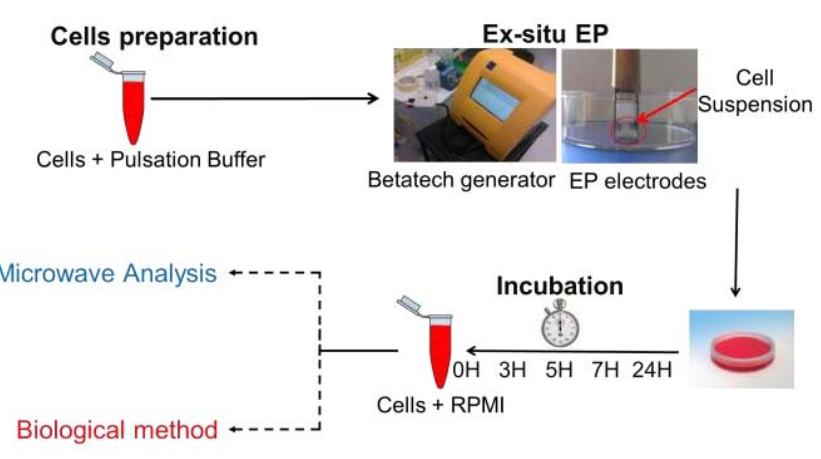

Fig. 2. Biological preparations for the experimental protocol.

cell's dielectric properties is obtained, which makes it possible to reveal, in real time, the state of the cell. The mechanical trap configuration not only permits to immobilize a single cell in the sensing area, where electromagnetic waves are concentrated, but it also enables to easily use all kinds of surrounding liquid to the cells (including ionic liquids and not only sucrose, conversely to the dielectrophoretic solution [18]-[21], and to add chemical treatment to the culture medium of cells if required.

\section{B. Experimental Protocol}

Human monocytes THP1 cells are used in ourpaper. They are cultured in culture flasks with the Gibco Roswell Park Memorial Institute 1640 medium premixed with $10 \%$ of fetal bovine serum and a mixture of antibiotics (100 Unity $/ \mathrm{mL}$ of penicillin and $100 \mu \mathrm{g} / \mathrm{mL}$ of streptomycin). Cells are incubated at $37{ }^{\circ} \mathrm{C}$ and under $5 \%$ of $\mathrm{CO} 2$ for proliferation.

For electroporation, electric pulses are delivered to the cells using a Betatech pulse generator with two stainless steel electrodes with a distance of $4 \mathrm{~mm}$. Cells are put in a pulsation buffer ZAP prior to pulsation, which has the following composition: $10 \mathrm{~mm}$ K2HPO4/KH2PO4, $1 \mathrm{~mm}$ $\mathrm{MgCl} 2,250 \mathrm{~mm}$ of sucrose, $\mathrm{pH} \mathrm{7.4}$. The used electrical parameters are defined based on the type of electroporation, we wanted to induce: a reversible or irreversible one. The definition of these parameters is explained in the Section III.

The protocol used is shown in Fig. 2. First, cells are electrically stressed, then reincubated at $37{ }^{\circ} \mathrm{C}$ and $5 \% \mathrm{CO}_{2}$ for $3,5,7$ or $24 \mathrm{~h}$. After this incubation time, cells are either injected in the microwave bio-device or studied with the biological method (flow cytometry or trypan blue test) 


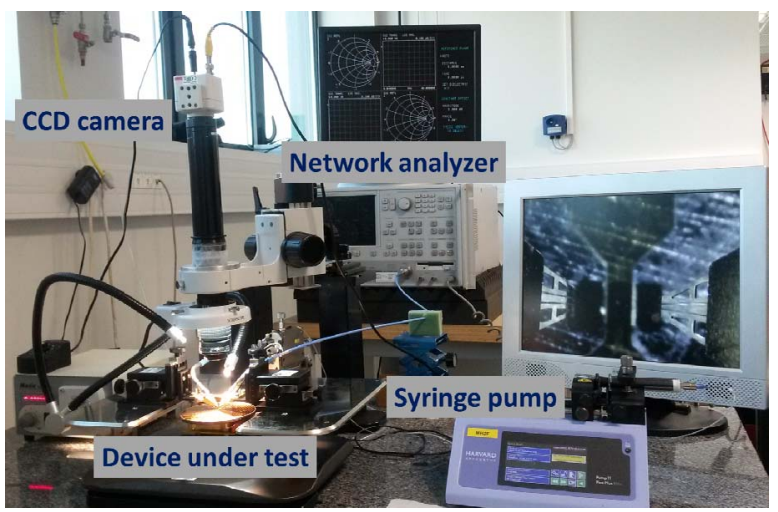

Fig. 3. Photograph of the microwave test setup.

in order to compare both results. The microwave test setup is shown in Fig. 3. The cell suspension is injected with the syringe pump in the microfluidic channel of the device under test, which is connected to the network analyzer via cables and microprobes. The whole setup is monitored by a CCD camera. For each condition, at least ten microwave measurements have been realized.

In order to evaluate the permeabilization rate after application of electric pulses, cells are put in the presence of PI. It is a small nonpermeant molecule, that intercalates in the nucleic acids (DNA or RNA) of the nucleus of cells that lost their membrane integrity [23]. We visualize the fluorescence emitted with the DMIRB-cool snap FxHQ2 (mCherry Filter) and the quantification of the permeability rate is assessed with the flow cytometer (Facscalibur, IPBS).

In thispaper, the viability of our cells after any kind of treatment is estimated either with the flow cytometer coupled to the PI molecule or with the Trypan Blue dye. The latter is a specific dye that instantly penetrates into the cells with permeabilized/damaged cytoplasmic membranes.

\section{Choice of Electrical Parameters FOR ELECTROPORATION}

Not all types of cell lines respond in the same way, when subjected to electric pulses. For this reason, a mandatory step was applied: the study of THP1 response to electric pulses in term of permeability and viability in order to choose the convenient intensity of the electrical pulse throughout this work. The other parameters (number, duration, and frequency of the pulses) are kept constant.

After treating different groups of cells with different intensities of electric field (without EP for the control test and from 0.4 to $2 \mathrm{kV} / \mathrm{cm}$ for the other groups), we quantified the percentage of permeabilized cells (Fig. 4). The photos show (a) THP1 cells in white light and (b) the fluorescence emitted from nontreated (negative control) and (c) permeabilized cells (at $1 \mathrm{kV} / \mathrm{cm}$ ). The fluorescing cells present in the negative control photo represent the basal level of cell death of this cell line. Fig. 4(d) shows the dependence of membrane permeabilization on the electric field intensity. The penetration of PI is significantly detected as of $0.6 \mathrm{kV} / \mathrm{cm}$ and reaches its maximal value around $1 \mathrm{kV} / \mathrm{cm}$.

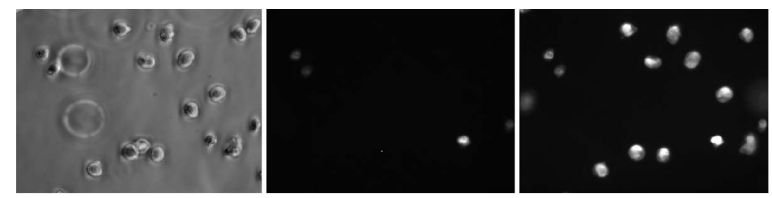

(a)

(b)

(c)

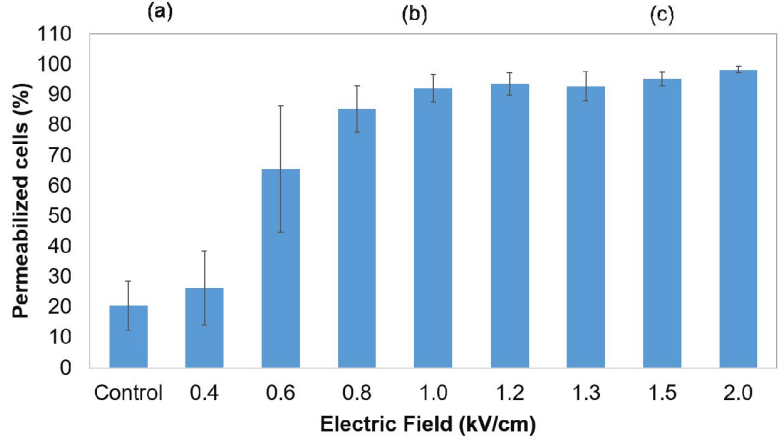

(d)

Fig. 4. Evaluation of THP1 permeability after EP by Propidium Iodide intake. Photographies of (a) THP1 cells with white light, (b) THP1 cells with PI and no EP, and (c) THP1 cells with PI and EP at $1 \mathrm{kV} / \mathrm{cm}$. (d) Percentage of permeabilized cells after EP.

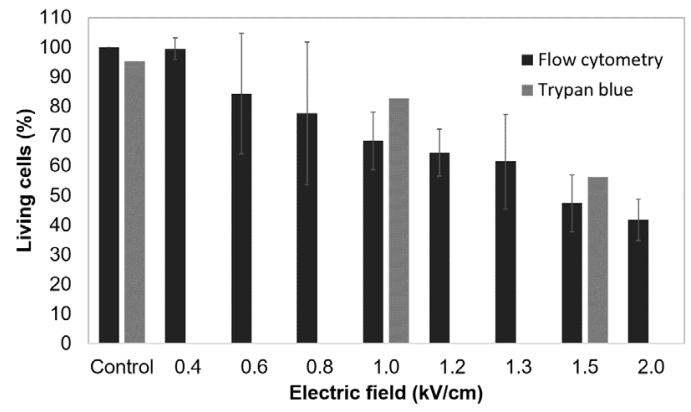

Fig. 5. Evaluation of THP1 viability after EP by flow cytometry and trypan blue.

A good compromise should be done when choosing the right parameters in a way that we have a high permeabilization rate along with preserving a high viability rate. For this purpose, viability assays are conducted $24 \mathrm{~h}$ after electroporation. Fig. 5 shows the percentage of viable cells $24 \mathrm{~h}$ after electroporation with two biological methods: the flow cytometry and the Trypan Blue test. As expected, when increasing the amplitude of the electric pulses and the cell viability decreases. This is due to the inability of the cells to reseal the pores and recover after this shock. Therefore, for the rest of the study, we use the following parameters, based on the desired type of electroporation:

1) reversible electroporation: 8 pulses of $1 \mathrm{kV} / \mathrm{cm}$ with a pulse duration of $100 \mu \mathrm{s}$ and at a frequency of $1 \mathrm{~Hz}$;

2) irreversible electroporation: 8 pulses of $1.5 \mathrm{kV} / \mathrm{cm}$ with a pulse duration of $100 \mu \mathrm{s}$ and at a frequency of $1 \mathrm{~Hz}$.

\section{Microwave Modeling of Single Cell}

The microwave measurements are performed on wafer in a range of frequencies from $40 \mathrm{MHz}$ to $40 \mathrm{GHz}$. The biosensor, shown in Fig. 1 and described in [24], is associated to an electrical model, which consider the coplanar waveguide access lines, the SU8 microfluidic walls and the capacitive sensing zone as shown in the Fig. 6(a). 


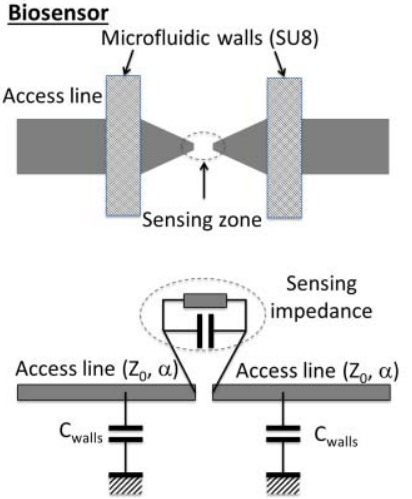

(a)
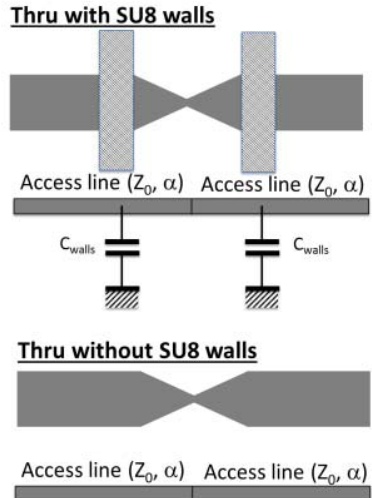

(b)
Thru without SU8 walls

Fig. 6. Biosensor electrical model.

Prior to any measurement, we characterize two calibration elements: 1) the thru with the SU8 walls, which corresponds to the biosensor structure where the sensing zone is suppressed and replaced by a thru connection and 2) the thru without the SU8 walls, for which the SU8 layer is suppressed. Fig. 6(b) shows these calibration elements and their associated electrical schematics. With these elements and by fitting the $S$ parameters of the measurements with those of the models, we determine the characteristic impedance $\left(Z_{0}\right)$ and attenuation coefficient $(\alpha)$ of the access lines as well as the SU8 walls' capacitance. Finally, using ABCD matrix de-embedding technique, we extract the sensing impedance of the sensing zone from the measured $S$-parameters of the biosensor [25], [26].

Then we follow the following procedure: the culture medium (without cells) is first injected and measured; this is our reference medium. After the injection of the cell suspension, a second set of measurements is performed once a single cell is captured inside the blocker, on top of the sensing zone. The extracted information from the sensing volume [17], the effective capacitance $C$ and conductance $G$, are compared with the reference medium by calculating the respective contrasts

$$
\begin{aligned}
\Delta C_{\text {eff }} & =C_{\text {cell }}-C_{\text {reference medium }} \\
\Delta G_{\text {eff }} & =G_{\text {cell }}-G_{\text {reference medium }}
\end{aligned}
$$

where $C_{\text {cell }}$ and $C_{\text {reference medium }}$ correspond to the respective capacitance when the sensor is loaded with a cell or with the reference medium only, and similarly for $G_{\text {cell }}$ and

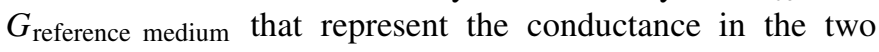
previously mentioned configurations.

The plain curves in Fig. 7 represent the respective measured spectra of (a) capacitive and (b) conductive contrasts of both a living and a saponin-treated cell $(0.02 \%)$. Saponin is a detergent, that makes the lipid bilayer permeable to macromolecules. The saponin-lysed cells do not reseal, indicating thus an irreversible damage of the lipid bilayer [27].

As shown in Fig. 7, both contrasts decrease (in absolute values) after exposure to the saponin molecule for $15 \mathrm{~min}$, reflecting the permeabilization of the cell membrane. Each condition was tested at least three times $(\mathrm{n}=3)$, and a total of 50 cells is analyzed per condition. This result is

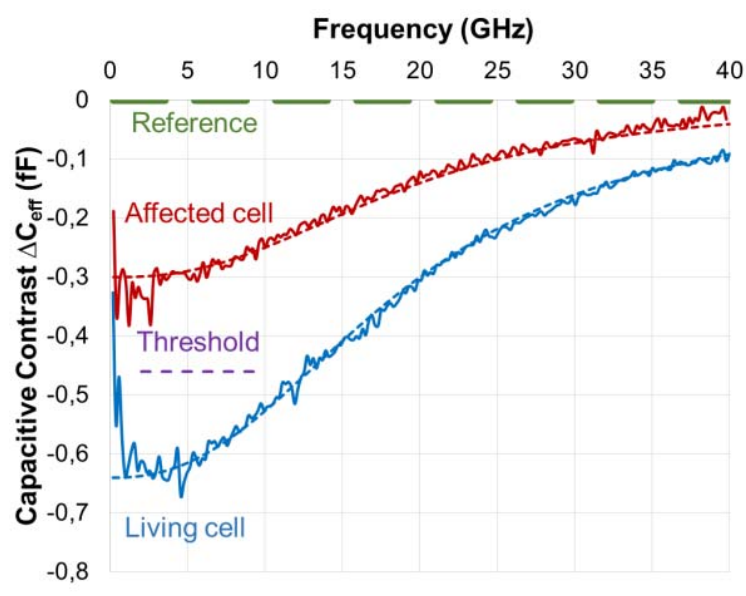

(a)

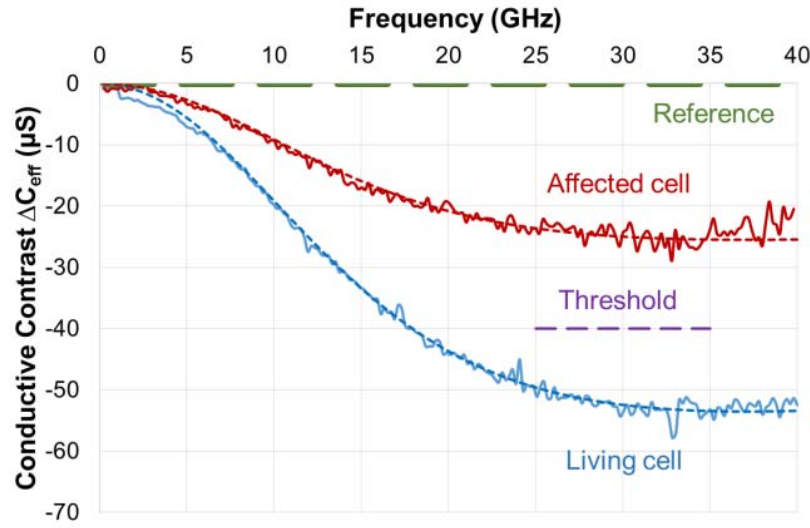

(b)

Fig. 7. Contrast of a living cell and an affected cell after treatment with $0.02 \%$ Saponin. (a) Capacitive contrast. (b) Conductive contrast. Cells measurements are performed in culture medium, which serves as reference.

in agreement with other publications. In particular, the work presented in [28] shows distinct differences in return loss $S_{11}$ and insertion loss $S_{21}$ of living and dead biological cells.

These contrasts variations ( $\Delta C_{\text {eff }}$ and $\Delta G_{\text {eff }}$ ) clearly point out the dispersive behavior of the high water content of the cell. To model this phenomenon, we consider a physical electrical schematic, derived from the Debye model [29] (dashed curves).

The physical (Debye-based) model of the single cell consists in a capacitor $\left(\Delta C_{\text {cell }}\right)$ placed in series with a resistor $\left(\Delta R_{\text {cell }}\right)$, which reflects the relaxation phenomenon of the aqueous solution inside the cell. The relationships between the effective capacitive and conductive contrasts and the Debye-based model are

$$
\begin{aligned}
& \Delta C_{\text {eff }}=\frac{\Delta C_{\text {cell }}}{1+\left(\Delta C_{\text {cell }} \times \Delta R_{\text {cell }} \times \omega\right)^{2}}=\frac{\Delta C_{\text {cell }}}{1+\left(\frac{f}{f_{\tau}}\right)^{2}} \\
& \Delta C_{\text {eff }}=\frac{\left(\Delta C_{\text {cell }}\right)^{2} \times \Delta R_{\text {cell }} \times \omega^{2}}{1+\left(\Delta C_{\text {cell }} \times \Delta R_{\text {cell }} \times \omega\right)^{2}}=\frac{\Delta C_{\text {cell }} \times \omega}{1+\left(\frac{f}{f_{\tau}}\right)^{2}} \times \frac{f}{f_{\tau}}
\end{aligned}
$$


TABLE I

Extracted $\Delta C_{\text {cell }}$ AND $f_{\tau}$ Debye's Parameters For BOTH LIVING AND AFFECTED CELLS

\begin{tabular}{ccc}
\hline \hline & $\Delta \mathrm{C}_{\text {cell }}$ & $\mathrm{f}_{\tau}$ \\
Living cell & $-0.65 \mathrm{fF}$ & $19 \mathrm{GHz}$ \\
Affected cell & $-0.30 \mathrm{fF}$ & $19 \mathrm{GHz}$ \\
Threshold & $-0.47 \mathrm{fF}$ & - \\
\hline \hline
\end{tabular}

where $f_{\tau}$ corresponds to the relaxation frequency of the intracellular aqueous cytoplasm and is given by

$$
f_{\tau}=\frac{1}{2 \pi \times \Delta C_{\text {cell }} \times \Delta R_{\text {cell }}} .
$$

With this model, $\Delta C_{\text {cell }}$ and $f_{\tau}$ for both living and affected cells have been extracted. These values are summarized in Table I. First, the $f_{\tau}$ value is not changed when the cell is affected compared with the living cell. Conversely, $\Delta C_{\text {cell }}$ values exhibit significant variation $(-53 \%)$ between living $(-0.64 \mathrm{fF})$ and affected $(-0.30 \mathrm{fF})$ cells.

This may be explained by the fact that the affected cell features a permeable membrane exhibiting greater molecular and ionic exchanges with the surrounding medium. The capacitive contrast is consequently less important when liquid exchanges arise, to reach equilibrium between the intra and extracellular media. This study allowed us to define a threshold value between alive and dead (i.e., affected) cells at the middle of the measured dynamics: $\Delta C_{\text {threshold }}=-0.47 \mathrm{fF}$. This threshold will be used in the next paragraph for cell screening depending on the viability.

\section{EVALUATION OF ELECTROPORATION INTENSITY EFFECT}

As explained earlier, the reversibility of the electroporation depends on the electrical parameters applied: a low voltage will induce a reversible electroporation and the cell will return to its normal state, whereas a high voltage will induce permanent damages and the cell will not be able to recover.

First, we have evaluated the ability of the dielectric spectroscopy to detect the effect of using different electric field intensities on living cells. For that, cells are subjected to 1 or $1.5 \mathrm{kV} / \mathrm{cm}$ (reversible and irreversible EP respectively) before being incubated for $24 \mathrm{~h}$ at $37{ }^{\circ} \mathrm{C}$. At least ten cells are measured in each condition. Next, a step of results sorting and classification is done, by referring to the thresholds previously established.

The mean values of the capacitive contrasts, are presented in Fig. 8. The percentages of cells, viable or affected by the electroporation, are also shown. In comparison to the control cells (nontreated), that present $88 \%$ of viability rate, reversible electroporation does not induce an important effect on the cells viability ( $\sim 95 \%)$; whereas by applying IRE, a decrease in the viability level down to $55 \%$ is observed.

Trypan blue test (biological test) is used to further validate the efficacy of our technique (cf. Fig. 9). A statistical analysis revealed a sharp correlation between the two methods of analysis $\left(R^{2} " \Delta C_{\text {cell }} /\right.$ Biological method" $\left.=0.98\right)$ indicating the

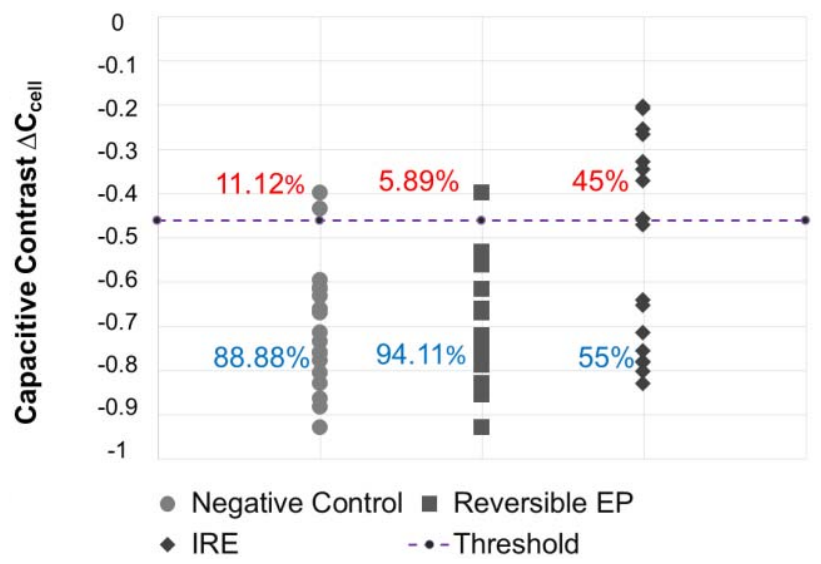

Fig. 8. Mean values of the capacitive contrasts (at $5 \mathrm{GHz}$ ) obtained $24 \mathrm{~h}$ after reversible and irreversible electroporation. Percentages of viable and affected cells are indicated.

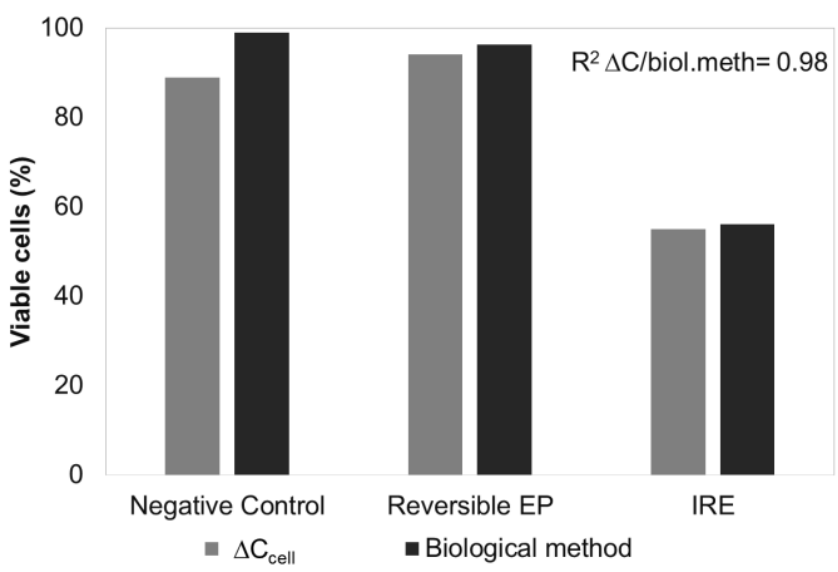

Fig. 9. THP1 response to increasing electric field estimated by microwave measurements (contrasts of capacitance and conductance) and by biological method (trypan blue).

robustness of the dielectric spectroscopy technique in detecting the effect of the reversible and irreversible electroporation on THP1 cells.

\section{Vi. Monitoring OF the Kinetics of IRREVERSIBLE ELECTROPORATION}

After validating the success of the dielectric spectroscopy in detecting the effect of reversible and irreversible EP on cells, we have investigated the kinetics related to cell's response to irreversible electroporation.

Fig. 10 shows the percentage of viable cells after electroporation with both biological and microwave techniques (only the capacitive contrast of the cells). In comparison to the control cells presenting a viability rate of $73 \%$, IRE induces a viability decrease down to $50 \%$ after 3 and $5 \mathrm{~h}$ and down to $40 \%$ after $7 \mathrm{~h}$ post IRE. $24 \mathrm{~h}$ after electroporation, the viability rate increases up to $50 \%$ and we hypothesis that it is due to the proliferation of remaining viable cells after treatment, as the cell cycle of THP1 is of the order of $24 \mathrm{~h}$. After performing a statistical analysis, a robust correlation coefficient $R^{2}$ between the microwave measurements compared with flow cytometry 


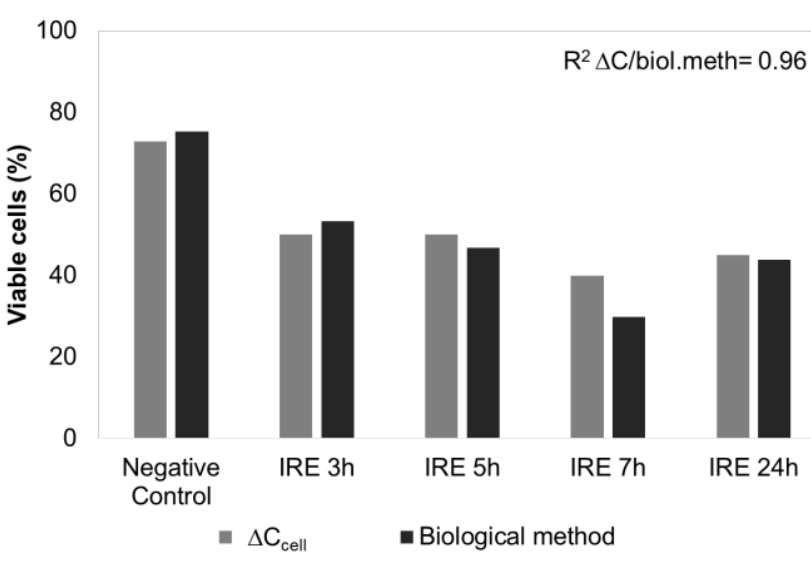

Fig. 10. Monitoring of kinetics of the response of THP1 after exposure to irreversible electroporation and correlation between microwave measurements and biological method.

data $\left(R^{2}=0.96\right.$ for correlation between $\Delta C_{\text {cell }}$ and the biological method) is deduced. These correlations audibly show the ability and robustness of our microwave and microfluidicbased technique in giving access and monitoring the effects of electroporation on cells. Furthermore, the microwave technique presents a number of assets making it very promising in the field of research, namely the fact that it is nondestructive, marker less, and compatible with cells directly measured in their culture medium.

\section{CONCLUSION}

In this paper, we demontrated that the microwave dielectric spectroscopy performed at the level of a single biological cell is able to discriminate the reversible and irreversible electroporations. All the more, it does not only reveal the cell's damages after treatment with irreversible electroporation but it also enables the monitoring of these damages over time. Aside from dielectric measurements, biological investigations (based on flow cytometry and trypan blue staining) undeniably indicate that microwave results have a strong correlation ( $R^{2}$ of 0.96 on $\Delta C_{\text {cell }}$ ) with these biological standard techniques. These results confirm that the proposed technique may contribute to having more insights and information the effect of electroporation and electrochemotherapy on different types of cells. It may therefore enrich the technique's arsenal of single cell analysis, within the context of the fight against cancer and beyond.

\section{REFERENCES}

[1] T. Kotnik, W. Frey, M. Sack, S. H. Meglič, M. Peterka, and D. Miklavčič, "Electroporation-based applications in biotechnology," Trends Biotechnol., vol. 33, no. 8, pp. 480-488, Aug. 2015.

[2] J. Teissie, M. Golzio, and M. P. Rols, "Mechanisms of cell membrane electropermeabilization: A minireview of our present (lack of ?) knowledge," Biochim. Et Biophys. Acta, vol. 1724, no. 3, pp. 270-280, Aug 2005 .

[3] E. Neumann and K. Rosenheck, "Permeability changes induced by electric impulses in vesicular membranes," J. Membrane Biol., vol. 10, no. 1, pp. 279-290, Dec. 1972.

[4] M. P. Rols and J. Teissié, "Electropermeabilization of mammalian cells. Quantitative analysis of the phenomenon," Biophys. J., vol. 58, no. 5, pp. 1089-1098, Nov. 1990.
[5] H. Wolf, M. P. Rols, E. Boldt, E. Neumann, and J. Teissié, "Control by pulse parameters of electric field-mediated gene transfer in mammalian cells," Biophys. J., vol. 66, no. 2, pp. 524-531, Feb. 1994.

[6] A. Maček-Lebar and D. Miklzvčič, "Cell electropermeabilization to small molecules in vitro: Control by pulse parameters," Radiol. Oncol., vol. 35, no. 3, pp. 193-202, Jan. 2001.

[7] M.-P. Rols and J. Teissié, "Electropermeabilization of mammalian cells to macromolecules: Control by pulse duration," Biophys. J., vol. 75 , no. 3, pp. 1415-1423, Sep. 1998.

[8] G. Pucihar, L. M. Mir, and D. Miklavčič, "The effect of pulse repetition frequency on the uptake into electropermeabilized cells in vitro with possible applications in electrochemotherapy," Bioelectrochemistry, vol. 57, no. 2, pp. 167-172, Sep. 2002.

[9] B. Rubinsky, G. Onik, and P. Mikus, "Irreversible electroporation: A new ablation modality-Clinical implications," Technol. Cancer Res. Treat, vol. 6, no. 1, pp. 37-48, Feb. 2007.

[10] J. Teissié and M. P. Rols, "An experimental evaluation of the critical potential difference inducing cell membrane electropermeabilization," Biophys. J., vol. 65, no. 1, pp. 409-413, Jul. 1993.

[11] S. Seo, T. Stintzing, I. Block, D. Pavlidis, M. Rieke, and P. G. Layer, "High frequency wideband permittivity measurements of biological substances using coplanar waveguides and application to cell suspensions," in IEEE MTT-S Int. Microw. Symp. Dig., Jun. 2008, pp. 915-918.

[12] T. Sun and H. Morgan, "Single-cell microfluidic impedance cytometry: A review," Microfluidics Nanofluidics, vol. 8, no. 4, pp. 423-443, 2010.

[13] D. A. Dean, T. Ramanathan, D. Machado, and R. Sundararajan, "Electrical impedance spectroscopy study of biological tissues," J. Electrostat., vol. 66, nos. 3-4, pp. 165-177, Mar. 2008.

[14] G. Mernier, N. Piacentini, R. Tornay, N. Buffi, and P. Renaud, "Cell viability assessment by flow cytometry using yeast as cell model," Sens. Actuators B, Chem., vol. 154, no. 2, pp. 160-163, Jun. 2011.

[15] C. Dalmay, J. Leroy, A. Pothier, and P. Blondy, "Development of high frequency microfluidic biosensors for intracellular analysis," in Proc. Eurosensors, XVIII ed., vol. 87, 2014, pp. 54-57.

[16] K. Grenier et al., "Recent advances in microwave-based dielectric spectroscopy at the cellular level for cancer investigations," IEEE Trans. Microw. Theory Techn., vol. 61, no. 5, pp. 2023-2030, May 2013.

[17] T. Chen, F. Artis, D. Dubuc, J.-J. Fournie, M. Poupot, and K. Grenier, "Microwave biosensor dedicated to the dielectric spectroscopy of a single alive biological cell in its culture medium," in IEEE MTT-S Int. Microw. Symp. Dig., Jun. 2013, pp. 1-4.

[18] Y. Yang et al., "Distinguishing the viability of a single yeast cell with an ultra-sensitive radio frequency sensor," Lab Chip, vol. 10, pp. 553-555, Jan. 2010.

[19] G. A. Ferrier, S. F. Romanuik, D. J. Thomson, G. E. Bridges, and M. R. Freeman, "A microwave interferometric system for simultaneous actuation and detection of single biological cells," Lab Chip, vol. 9, no. 23, pp. 3406-3412, Oct. 2009.

[20] Y. Ning et al., "Broadband electrical detection of individual biological cells," IEEE Trans. Microw. Theory Techn., vol. 62, no. 9, pp. 1905-1911, Sep. 2014.

[21] H. Li, X. Ma, X. Du, X. Cheng, and J. C. M. Hwang, "High-frequency continuous-wave electroporation of jurkat human lymphoma cells," in IEEE MTT-S Int. Microw. Symp. Dig., May 2016, pp. 1-4.

[22] A. Tamra, M. Deburghgraeve, D. Dubuc, M.-P. Rols, and K. Grenier, "Microwave dielectric spectroscopy for single cell irreversible electroporation monitoring," in IEEE MTT-S Int. Microw. Symp. Dig., May 2016, pp. $1-4$.

[23] V. L. Sukhorukov et al., "Surviving high-intensity field pulses: Strategies for improving robustness and performance of electrotransfection and electrofusion," J. Membrane Biol., vol. 206, no. 3, pp. 187-201, Jun. 2005.

[24] W. Chen, D. Dubuc, and K. Grenier, "Microwave dielectric spectroscopy of a single biological cell with improved sensitivity up to $40 \mathrm{GHz}$," in IEEE MTT-S Int. Microw. Symp. Dig., May 2015, pp. 1-3.

[25] K. Grenier et al., "Integrated broadband microwave and microfluidic sensor dedicated to bioengineering," IEEE Trans. Microw. Theory Techn., vol. 57, no. 12, pp. 3246-3253, Dec. 2009.

[26] J. C. Booth, N. D. Orloff, J. Mateu, M. Janezic, M. Rinehart, and J. A. Beall, "Quantitative permittivity measurements of nanoliter liquid volumes in microfluidic channels to $40 \mathrm{GHz}$," IEEE Trans. Instrum. Meas., vol. 59, no. 12, pp. 3279-3288, Dec. 2010.

[27] E. Baumann, G. Stoya, A. Völkner, W. Richter, C. Lemke, and W. Linss, "Hemolysis of human erythrocytes with saponin affects the membrane structure," Acta Histochem., vol. 102, no. 1, pp. 21-35, Feb. 2000. 
[28] X. Ma et al., "Reproducible broadband measurement for cytoplasm capacitance of a biological cell," in IEEE MTT-S Int. Microw. Symp. Dig., May 2016, pp. 1-4.

[29] K. R. Foster and H. P. Schwan, "Dielectric properties of tissues," in Handbook of Biological Effects of Electromagnetic Fields, C. Polk and E. Postow, Eds. Boca Raton, FL, USA: CRC Press, 1996, ch. 1.

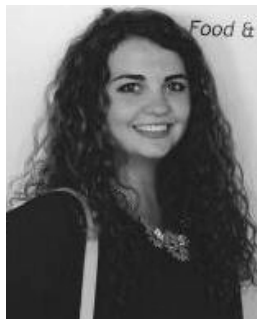

Amar Tamra (S'16-A'16) received the M.S. degree in molecular diagnostics from the Faculty of Sciences, Lebanese University, Beirut, Lebanon, in 2013. She is currently pursuing the Ph.D. degree at the University of Toulouse, Toulouse, France.

She is currently with the Laboratory of Analysis and Architecture of System, National Scientific Research Center, Toulouse. Her current research interests include the use of microwave based dielectric spectroscopy for the study and the characterization of electroporation and electro-transfer of drugs

into human cancer cells.

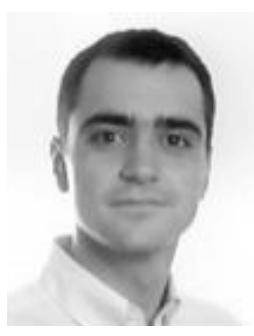

David Dubuc (S'99-M'03) received the Agregation degree from the Ecole Normale Supérieure de Cachan, Paris, France, in 1996, and the M.S. and $\mathrm{Ph} . \mathrm{D}$. degrees in electrical engineering from the University of Toulouse, Toulouse, France, in 1997 and 2001, respectively.

Since 2013, he has been a Professor with the University of Toulouse/LAAS-CNRS. From 2002 to 2013, he was an Associate Professor with the University of Toulouse, and a Researcher with the Laboratory of Analysis and Architecture of System part of the National Scientific Research Center (CNRS), Toulouse. From 2007 to 2009, he was a Visiting Senior Researcher with the Laboratory of Integrated Micromechatronic Systems CNRS/Institute of Industrial Science, University of Tokyo, Tokyo, Japan. Since 2013, he has been a Professor with the University of Toulouse. His current research interests include the development of microwave circuits integrated due to microtechnologies and their application to wireless telecommunication and biology.

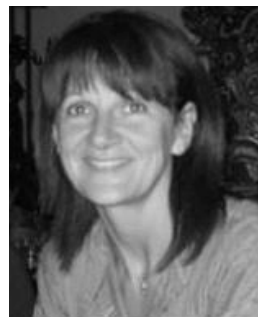

Marie-Pierre Rols received the master's degree in biochemistry, Ph.D. degree in cell biophysics, and habilitation à Diriger les Recherches from the Paul Sabatier University of Toulouse, Toulouse, France, in 1984, 1989, and 1995, respectively.

She is currently the Director of Research with the Institute of Pharmacology and Structural BiologyCentre National de la Recherche Scientifique Laboratory, Toulouse, where she is the Vice-Secretary of the Groupe Thématique de recherche sur la Vectorologie. She has authored over 100 papers in peerreviewed journals. Her previous research interests include the mechanism of DNA electrotransfer. Her current research interests include membrane electropermeabilization in vitro and in vivo.

Dr. Rols is a member of the Management Committee of the COST TD1104European network for development of electroporation-based technologies and treatments (EP4Bio2Med) and a member of the Groupe d'Etude des Membranes. She was a recipient of the Galvani Prize of the Bioelectrochemical Society in 1993 and the joined prize of the Midi-Pyrénées Region in 2006.

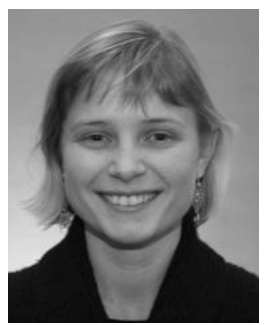

Katia Grenier (S'99-M'03) received the M.S. and $\mathrm{Ph} . \mathrm{D}$. degrees in electrical engineering from the University of Toulouse, Toulouse, France, in 1997 and 2000, respectively.

She was involved in microelectromechanical systems circuits on silicon. She was a Post-Doctoral Fellow with Agere Systems, Bell Labs, Allentown, PA, USA. From 2007 to 2009, she was with the Laboratory for Integrated Micromechatronic Systems CNRS /Institute of Industrial Science, Universtity of Tokyo, Tokyo, Japan, where she was involved in launching research activities on microwave-based biosensors. In 2001, she joined the Laboratory of Analysis and Architecture of System of the National Scientific Research Center (LAAS-CNRS), Toulouse. Her current research interests include the development of fluidic-based microsystems, notably for biological and medical applications at the cellular and molecular levels.

Dr. Grenier is a member of the IEEE MTT-10 Technical Committee on Biological Effect and Medical Applications of RF and Microwave of the IEEE Microwave Theory and Techniques Society. 